\title{
Studies on Highly Dense Pure YIG Polycrystalline Ceramics Fabricated by Tape-casting Method
}

\section{Chong Zhao}

Renmin University of China

\section{Yingkui Li}

Songshan Lake Materials Laboratory

Xiaofei Shen

Songshan Lake Materials Laboratory

\section{Zhijun Cao}

University of Virginia

\section{Zhiquan Cao}

New York University

\section{Zicheng Wen}

Songshan Lake Materials Laboratory

\section{Xuanyi Yuan}

Renmin University of China

\section{Chaoyang Ma}

Songshan Lake Materials Laboratory

\section{Yongge Cao ( $\sim$ caoyongge@sslab.org.cn )}

Songshan Lake Materials Laboratory, Dongguan 523808, Guangdong, China Institute of Physics, Chinese Academy of Sciences, Beijing 100190, China

\section{Research Article}

Keywords: YIG ceramics, tape-casting, microwave, hysteresis loss, magnetodielectric ceramics

Posted Date: August 12th, 2020

DOI: https://doi.org/10.21203/rs.3.rs-57431/v1

License: (9) This work is licensed under a Creative Commons Attribution 4.0 International License. Read Full License 


\title{
Studies on highly dense pure YIG polycrystalline ceramics fabricated by tape-casting method
}

Chong $\mathrm{Zhao}^{\mathrm{a}}$, Yingkui $\mathrm{Li}^{\mathrm{b}}$, Xiaofei Shen ${ }^{\mathrm{b}}$, Zhijun $\mathrm{Cao}^{\mathrm{c}}$, Zhiquan $\mathrm{Cao}^{\mathrm{d}}$, Zicheng $\mathrm{Wen}^{\mathrm{b}, \mathrm{e}}$, Xuanyi Yuan ${ }^{\mathrm{a}}$, Chaoyang $\mathrm{Ma}^{\mathrm{b}, *}$, Yongge Cao ${ }^{\mathrm{be}, *}$

${ }^{a}$ Department of Physics, Renmin University of China, Beijing 100872, China

${ }^{\mathrm{b}}$ Songshan Lake Materials Laboratory, Dongguan 523808, Guangdong, China

${ }^{c}$ University of Virginia, Charlottesville, VA 22904, USA

${ }^{\mathrm{d}}$ New York University, New York, NY 10003, USA

${ }^{\mathrm{e}}$ Institute of Physics, Chinese Academy of Sciences, Beijing 100190, China

*Corresponding authors: caoyongge@ sslab.org.cn

machaoyang@sslab.org.cn

\begin{abstract}
Pure phase $\mathrm{Y}_{3} \mathrm{Fe}_{5} \mathrm{O}_{12}$ (YIG) ceramics was successfully produced by tape-casting forming process and one-step solid-state reaction method. With the sintering temperature above $1100{ }^{\circ} \mathrm{C}$, the pure phase YIG ceramics was synthesized with no YIP or $\mathrm{Fe}_{2} \mathrm{O}_{3}$ phase in XRD patterns. YIG ceramic sintering at $1400{ }^{\circ} \mathrm{C}$ for $10 \mathrm{~h}$ showed a clear grain structure with an obvious grain boundary, and no pores were observed in the SEM images. YIG ceramics in this paper has a high relative density which was $99.8 \%$ and the saturation magnetization was $28.2 \mathrm{emu} / \mathrm{g}$ at room temperature. The hysteresis loss at temperatures of 230-360 K was smaller than $10 \mathrm{~mJ} / \mathrm{kg}$. The $\tan \delta_{\varepsilon}$ was nearly zero at $6 \sim 7 \mathrm{GHz}$ and $11 \sim 12$ $\mathrm{GHz}$, showing that it can be used as a good material for microwave applications. In
\end{abstract}


addition, the low values of $\tan \delta_{\varepsilon}$ and $\tan \delta_{\mu}$ indicates that it may have a good electromagnetic wave absorption ability.

\section{Keywords}

YIG ceramics; tape-casting; microwave; hysteresis loss; magnetodielectric ceramics

\section{Introduction}

Yttrium iron garnet, $\mathrm{Y}_{3} \mathrm{Fe}_{5} \mathrm{O}_{12}$ (YIG) has a bcc cubic structure and belongs to the space group Ia-3d (230). Furthermore, per unit cell $\left(1895.6 \AA^{3}\right)$ contains 8 formula units, where $\mathrm{Y}^{3+}$ ions occupy the eight-coordinate $\left(\mathrm{O}^{2-}\right)$ dodecahedral sites, while $\mathrm{Fe}^{3+}$ ions partially take up six-coordinate octahedral and three-coordinate tetrahedral sites. YIG materials and its modifications by doping as soft ferrites are suitable for magnetic microwave devices with high frequency and low microwave loss [1,2]. Microwave filters and oscillators based on YIG have a wider electric tuning range in frequency than other candidates including ferroelectric and varactors [3]. Multiferroic magnetoelectric materials developed on YIG exhibit both ferroelectricity and ferromagnetism, and typically yield much larger magnetoelectric coupling response than natural multiferroic single-phase compounds, making them suitable for magneto-electric applications [4]. Faraday rotators with substituted YIG films or bulk crystals own large Faraday Rotation capacity, low saturation magnetization and low optical absorption loss, showing high potential applications in magneto-optical devices [5,6].

Pure polycrystalline Bi-substituted YIG thin films were grown on Corning glass substrates by an original CVD technique and its Faraday rotation properties were studied [7]. Bi-substituted Y-Yb mixed iron garnet single crystals were grown by the flux method and the specific Faraday Rotation, optical absorption coefficient and the 
saturation magnetization were investigated [5]. Nowadays, polycrystalline YIG (powder or bulk ceramic) are generally synthesized through conventional solid-state reaction (CSSR) method. For YIG ceramics, properties of density, purity and microstructure have great impact on the magnetic properties and therefore the performance of its microwave devices. However, some secondary phases $\left(\mathrm{Fe}_{2} \mathrm{O}_{3}, \mathrm{YFeO}_{3}, \mathrm{YFe}_{2} \mathrm{O}_{4}\right)$ are usually coexisted with YIG fabricated by CSSR method [8,9]. The growth kinetic and reaction mechanism of $\mathrm{Y}_{2} \mathrm{O}_{3}-\mathrm{Fe}_{2} \mathrm{O}_{3}$ system were studied by different diffusion couples. And, the results showed that the formation of YIG phases were highly depended on pre-formed YIP phases and the diffusion of $\mathrm{Fe}^{3+}$ cations [10-12]. By adding excess 8-10 wt $\% \mathrm{Fe}_{2} \mathrm{O}_{3}, 99 \%$ of YIG ceramic phase was achieved. What's more, YIG with properly excess $\mathrm{Fe}_{2} \mathrm{O}_{3}$ could be used for high frequency tunable dielectric resonator antenna (DRA) [13,14]. Recently, YIG ceramics with about $98-99 \%$ of theoretical density were fabricated by solid-state reaction method $[15,16]$. While, new fabrication methods are pursued for much higher dense and purity fine-grained YIG ceramics.

In this work, high-dense pure YIG polycrystalline ceramics were fabricated by tape-casting forming process and one-step solid-state reaction method. Phase purity, relative density and micro-morphology depends on sintering temperature and holding time were studied. The activation energy was calculated from the linear Arrhenius plots. XPS was performed to check valance states of $\mathrm{Fe}$ and $\mathrm{O}$ atoms, as well as EPR spectrum was introduced to check $\mathrm{O}$ vacancy. Thereafter, magnetic and dielectric properties were chractarized for the sample sintered at $1400^{\circ} \mathrm{C}$ for $8 \mathrm{~h}$.

\section{Material and methods}

Commercially available powders of $\mathrm{Y}_{2} \mathrm{O}_{3}(99.99 \%)$ and $\mathrm{Fe}_{2} \mathrm{O}_{3}(99.99 \%)$ were used as raw materials without further purifying. Powders were precisely weighted in accordance with 
the stoichiometry of $\mathrm{Y}_{3} \mathrm{Fe}_{5} \mathrm{O}_{12}$ and then added into the mixed solvent of ethanol and xylene. Besides, proper amount of TEOS (Tetraethyl Orthosilicate) as sintering aid and fish oil as dispersant were put into the mixture. Then, the mixed slurry was planetary ball-milled for 24 h. Subsequently, some binder (Polyvinyl Butyral), plasticizers (Polyalkylene Glycol \& Butyl Benzyl Phthalate) and defoamers (n-butyl alcohol \& ethylene glycol) were added and ball-milled for another $24 \mathrm{~h}$.

Thereafter, the tape-casting forming process was carried out. The distance between the blade and tape was $500 \mu \mathrm{m}$ and the casting speed was $500 \mathrm{~mm} / \mathrm{min}$. The prepared slurry on the tape was dried at room temperature, and then cut into slices. A proper number of layers of slices were stacked and compressed under $20 \mathrm{Mpa}$ at $120^{\circ} \mathrm{C}$ to form into green body. The green body was calcined at $800{ }^{\circ} \mathrm{C}$ in an oxygen atmosphere to remove organic additives, and then sintered at various temperatures in a furnace under air atmosphere. Finally, the obtained YIG ceramics were prepared for characterization.

The phase identification of the fabricated ceramics was performed on an XRD system (Bruker, Germany) using $\mathrm{Cu} K \alpha$ radiation $(\lambda=1.5406 \AA)$. The surface micro-morphology was carried on a field-emission SEM (JSM-6700F, JEOL, Japan). The XPS was conducted by using an X-ray photoelectron spectrometer (ESCALAB 250X, Thermo Scientific, USA). The EPR was conducted by using an electron paramagnetic resonance instrument (A300-10/12, Bruker, Germany). The bulk density was measured using the Archimedes' method. The magnetic hysteresis loops were obtained by a vibrating sample magnetometer (VSM, QD, USA). The magnetic and dielectric properties were determined with a microwave network analyzer (PNA-N5244A, Agilent, USA).

\section{Results and discussion}




\subsection{XRD}

Fig. 1 shows the XRD patterns of YIG ceramics fabricated by combining tape-casting forming process and solid-state reaction method at various sintering temperatures in air atmosphere. It can be clearly observed that the ceramics with sintering temperatures above $1100{ }^{\circ} \mathrm{C}$ are all YIG pure phases (PDF\# 71-2150). According to Ali's report, YIG ceramics prepared through dry-pressing forming process generally contain unwanted phase of YIP even with $1250{ }^{\circ} \mathrm{C}$ sintering temperature [10]. It is suggested that YIP is formed as an intermediate phase and will further react with $\mathrm{Fe}_{2} \mathrm{O}_{3}$ to produce single-phase YIG by diffusion process [12]. It is suggested that $\mathrm{Fe}^{3+}$ cations diffuse and initiate the $\mathrm{Fe}-\mathrm{Y}$ atomic bonding. Then, with $\mathrm{Fe}^{3+}$ cations continuously diffusing, the YIP layer covered on the surface of $\mathrm{Y}_{2} \mathrm{O}_{3}$ particles turned to be $\mathrm{YIG}$ while the inner $\mathrm{Y}_{2} \mathrm{O}_{3}$ changed into YIP. Considering the saturated vapor pressure of Fe and Y calculated by Eq. (1) and listed in Table 1, it can be seen that Fe has a larger saturated vapor pressure than Y, which signifies that the iron is more volatile in this system. If $\mathrm{Fe}_{2} \mathrm{O}_{3}$ is inhomogeneous in this system, high concentration of Fe element means more evaporation at high temperature. So, the existence of YIP impurity is highly depended on the inhomogeneous and evaporation of $\mathrm{Fe}_{2} \mathrm{O}_{3}$. Compared with dry-pressing forming method, our tape-casting forming method provide much better homogeneous mixture of $\mathrm{Y}_{2} \mathrm{O}_{3}$ and $\mathrm{Fe}_{2} \mathrm{O}_{3}$ particles, thus leading to the highly pure YIG ceramics.

$\log (\mathrm{p} / \mathrm{atm})=\mathrm{A}+\mathrm{B} / \mathrm{T}+\mathrm{C} * \log (\mathrm{T})+\mathrm{D} / \mathrm{T}^{3}$

Here, coefficients in the equation can be obtained from reference [17] and listed in Table 1.

Table 1. Vapor pressure of metallic elements Fe and $\mathrm{Y}$ in the solid state at about $1800 \mathrm{~K}$.

\begin{tabular}{|l|l|l|l|l|l|l|}
\hline Element & $\mathrm{A}$ & $\mathrm{B}$ & $\mathrm{C}$ & $\mathrm{D}$ & $\mathrm{T}(\mathrm{melt}) / \mathrm{K}$ & $\mathrm{P} / \mathrm{atm}$ \\
\hline $\mathrm{Fe}$ & 7.1 & -21723 & 0.4536 & -0.5846 & 1808 & $3.652 \times 10^{-4}$ \\
\hline
\end{tabular}




\begin{tabular}{|l|l|l|l|l|l|l|}
\hline $\mathrm{Y}$ & 9.735 & -22306 & -0.8705 & 0 & 1799 & $2.967 \times 10^{-6}$ \\
\hline
\end{tabular}

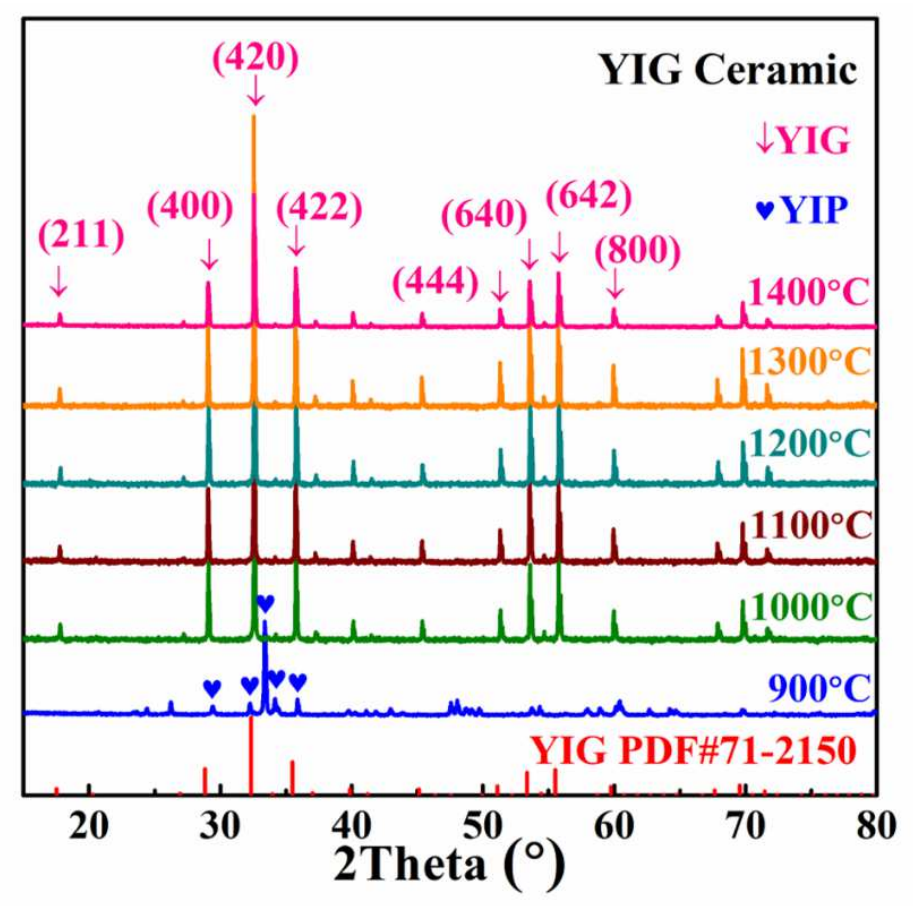

Fig. 1. The XRD patterns of YIG ceramics sintered under various temperatures in air atmosphere.

\subsection{SEM and XPS}

Figs. 2(a-f) show the SEM images of YIG ceramics prepared at various sintering temperatures for $10 \mathrm{~h}$ and the evolution of morphologies is in accord with Ostwald ripening process. Along with the sintering temperature increasing from 900 to $1400^{\circ} \mathrm{C}$, driven by the sintering kinetics, little grains gradually adhere to each other with grain boundaries and grow to be big grains to reduce the interfacial area, as a result, gaps and pores between grains are gradually eliminated at the same time. Samples sintered at $1400{ }^{\circ} \mathrm{C}$ exhibit no pores existed in both grains and boundaries, indicating a quite high densification, as 
discussed in Section 3.3. Grain size in Fig. 4(f) is non-uniform and varies from several microns to several dozens of microns, which can be ascribed to the asynchronous growth of grains at different regions and thereof migration of grain-boundaries, as shown in Figs. 2(a-e).

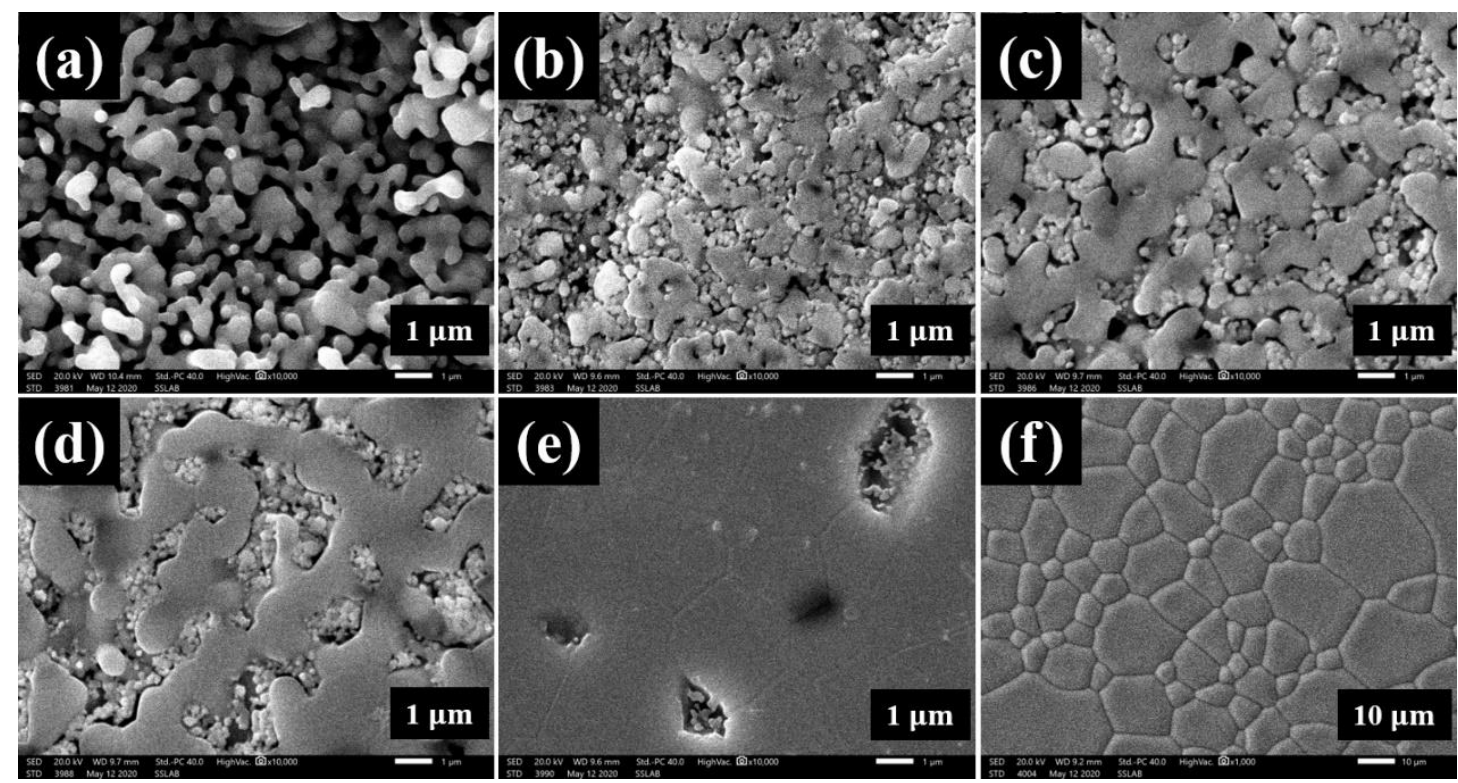

Fig. 2. SEM images of YIG ceramics sintered at (a) $900{ }^{\circ} \mathrm{C}$, (b) $1000{ }^{\circ} \mathrm{C}$, (c) $1100{ }^{\circ} \mathrm{C}$, (d) $1200{ }^{\circ} \mathrm{C}$, (e) $1300^{\circ} \mathrm{C}$ and (f) $1400{ }^{\circ} \mathrm{C}$ for $10 \mathrm{~h}$.

According to Chen's report, $\mathrm{Fe}^{2+}$ ions and oxygen vacancies may exist in ceramics fabricated by high temperature sintering process due to the low oxygen conditions [16], and this can be verified by XPS measurement. Fig. 3 shows XPS spectra of YIG ceramics sintered at $1400{ }^{\circ} \mathrm{C}$ for $10 \mathrm{~h}$. The XPS spectrum confirmed the existence of Fe $2 \mathrm{p}_{1 / 2}, \mathrm{Fe}$ $2 p_{3 / 2}, \mathrm{Fe} 3 \mathrm{~s}, \mathrm{Fe} 3 \mathrm{p}, \mathrm{O} 1 \mathrm{~s}, \mathrm{O} 2 \mathrm{~s}, \mathrm{Y} 3 \mathrm{~s}, \mathrm{Y} 3 \mathrm{p}_{1 / 2}, \mathrm{Y} 3 \mathrm{p}_{3 / 2}, \mathrm{C} 1 \mathrm{~s}, \mathrm{Y} 3 \mathrm{~d}, \mathrm{Y} 4 \mathrm{~s}$ and Y $4 \mathrm{p}$ signals for the sample as shown in Fig 3(a). In Fig. 3(b), based on the Lorentzian-Gaussian fitting, Fe $2 \mathrm{p}_{3 / 2}$ peak and $\mathrm{Fe} 2 \mathrm{p}_{1 / 2}$ peak can both be divided into $\mathrm{Fe}^{3+}$ and $\mathrm{Fe}^{2+}$ peaks which are centered at $711.6 \mathrm{eV}, 726.4 \mathrm{eV}, 710.2 \mathrm{eV}$ and $724.2 \mathrm{eV}$. Meanwhile, $\mathrm{O}$ 1s spectrum in Fig. 3(c) was divided into two peaks centered at $529.9 \mathrm{eV}$ and $531.6 \mathrm{eV}$. And the latter peak 
indicated the existence of oxygen vacancy which can also be proved by the EPR spectrum, as shown in the illustration in Fig. 3(c).
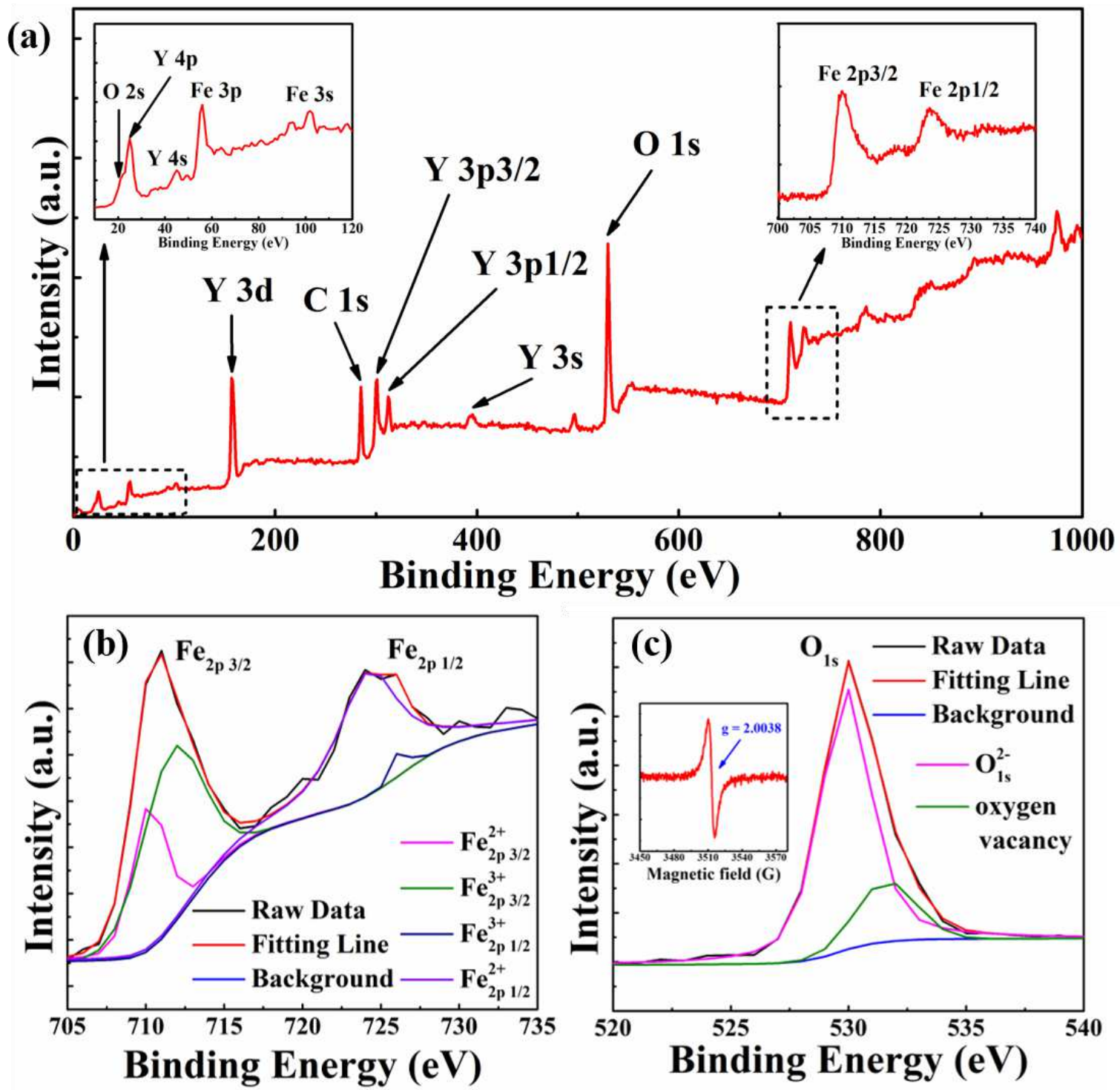

Fig. 3. XPS spectra in (a) the survey range, (b) Fe ion and (c) $\mathrm{O}$ ion in YIG ceramics sintered at $1400{ }^{\circ} \mathrm{C}$ for $10 \mathrm{~h}$.

\subsection{Relative density and activation energy}

The sintering kinetics, namely densification kinetics, of YIG ceramics could be characterized by the relationship between the relative density and sintering conditions (temperatures and holding times). Densities of YIG ceramics sintered at various 
temperatures and holding times were measured by Archimedes' method and were plotted in Fig. 4(a). Obviously, higher sintering temperature and longer holding time did lead to higher relative density. Besides, the relative density increased significantly along with the temperature below $1375^{\circ} \mathrm{C}$, while it increased slowly when the temperature further raised. For samples sintered at $1450{ }^{\circ} \mathrm{C}$ for $8 \mathrm{~h}$, the relative density reached the highest value of 99.8\%, which was bigger than that values reported in references [15] and [18]. The high relative density indicated extremely low residual porosity and highly dense microstructure. Densification kinetics can be interpreted by Arrhenius equation: $[10,18,19]$ $\ln K=-E_{a} / R T+C$ where, $E_{a}$ is the activation energy for YIG ceramic densification, $R$ is the gas constant $(8.314 \mathrm{~J} / \mathrm{mol} / \mathrm{K}), T$ is the absolute temperature, $C$ is the constant, and $K$ is the rate constant depending on temperature. Densification rate versus reciprocal temperature was plotted in Fig. 4(b), where rate constant $K$ was related to relative density and calculated from Fig. 4(a). By linear fitting, the value of $E_{a}$ was determined to be $183.81 \mathrm{~kJ} / \mathrm{mol}$, which was comparable with the activation energy of $169 \mathrm{~kJ} / \mathrm{mol}$ for lattice diffusion or grain boundary formation [18] and much smaller than the energy of $484 \mathrm{~kJ} / \mathrm{mol}$ for YIG formation from YIP [10]. It can be drawn that the mechanism of YIG phase formation and ceramics densification was the result of homogeneous diffusion probably assisted by the sintering aids of $\mathrm{SiO}_{2}$ (products of TEOS decomposition) located at grain boundaries. 

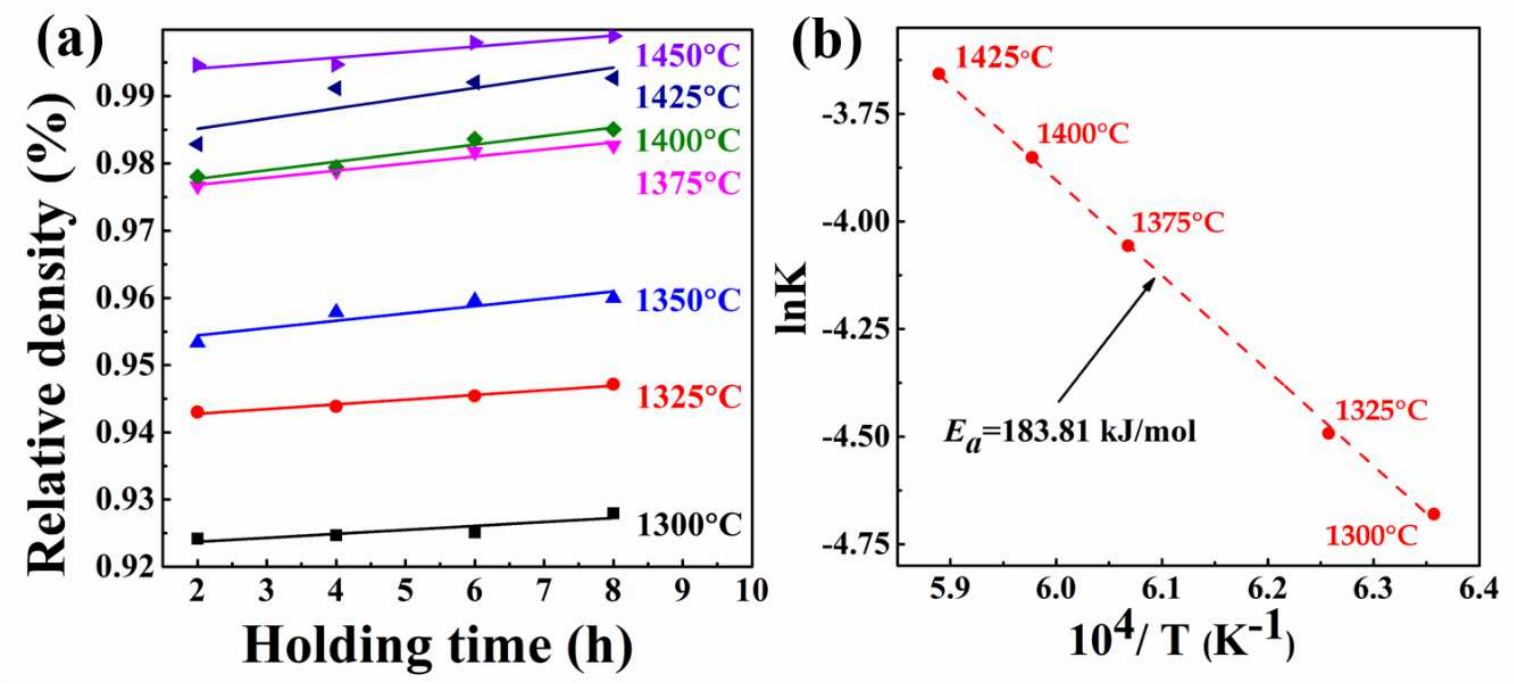

Fig. 4. (a) Relative densities of YIG ceramics sintered at various temperatures and holding times. (b) The activation energy analysis for YIG ceramics.

\subsection{Intrinsic magnetic property}

The magnetic properties of YIG ceramics sintered at $1400{ }^{\circ} \mathrm{C}$ were studied by the static hysteresis loops under various temperatures, as shown in Fig. 5(a). The well-defined hysteresis loop can be clearly observed at $30 \mathrm{~K}$, while turned to be narrower along with the increase of temperature. The saturation magnetization $\left(M_{s}\right)$ and hysteresis loss (area of the hysteresis loop) depending on temperature were plotted in Fig. 5(b). The value of $M_{s}$ decreased from $38.9 \mathrm{emu} / \mathrm{g}$ down to $25.3 \mathrm{emu} / \mathrm{g}$ as the temperature increased from $30 \mathrm{~K}$ up to $360 \mathrm{~K}$. And, the trend could be ascribed to the enhanced thermal vibrations of atoms and lattices under high temperatures, and hence magnetic dipoles were difficult to be aligned [20]. It was worth mentioning that the room-temperature $(300 \mathrm{~K})$ value of $M_{s}$ was 28.2 $\mathrm{emu} / \mathrm{g}$, which was a little higher than that value $(27.4 \mathrm{emu} / \mathrm{g})$ reported in previous literature [15]. The result indicated that our YIG ceramics exhibited much higher relative density and more compact microstructures. Hysteresis loss, characterized by the area of the hysteresis loop, generally decreased with temperature. However, in this work, there was an upturn 
point at $230 \mathrm{~K}(4 \mathrm{~mJ} / \mathrm{kg})$, and the mechanism needed to be further studied. Besides, hysteresis loss at $30 \mathrm{~K}$ was as high as $238.8 \mathrm{~mJ} / \mathrm{kg}$, while values of that at temperatures of 230-360 K was smaller than $10 \mathrm{~mJ} / \mathrm{kg}$.
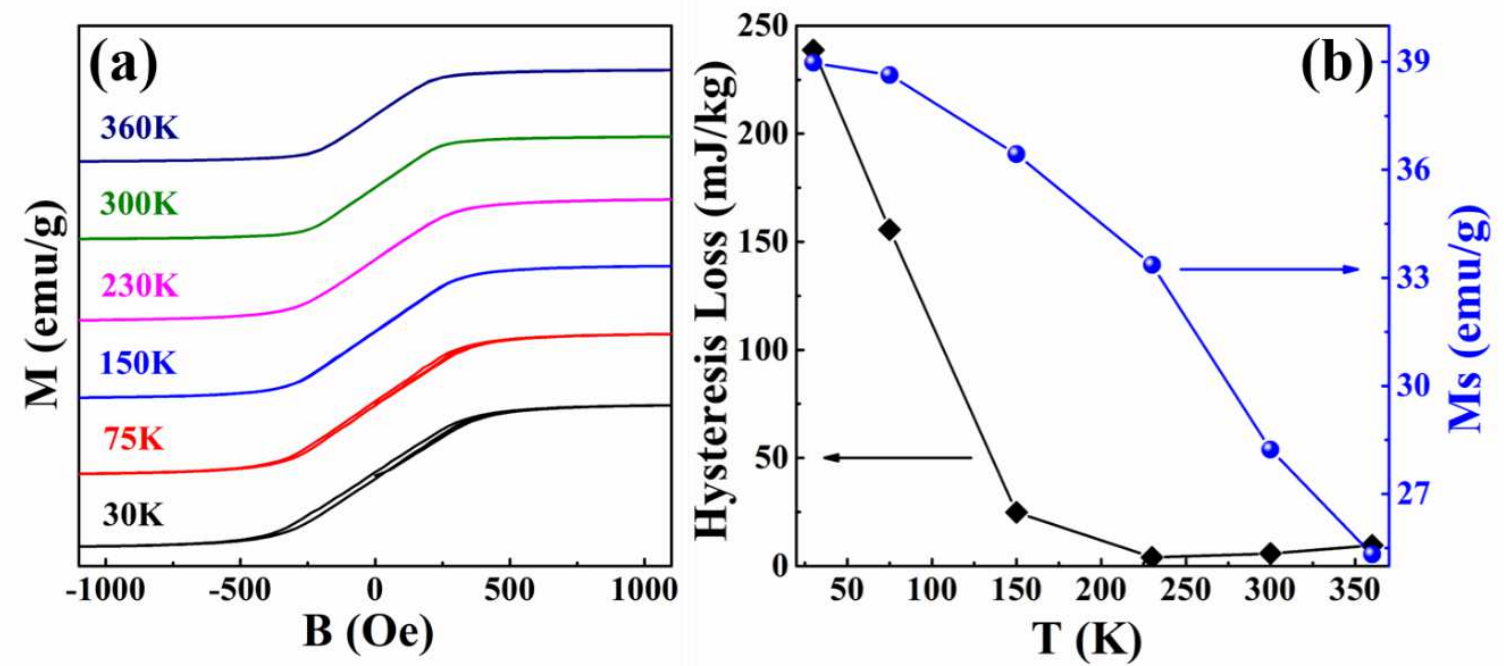

Fig. 5. (a) Magnetic hysteresis loops and (b) $M_{s}$ and hysteresis loss of YIG ceramics sintered at $1400{ }^{\circ} \mathrm{C}$ for $8 \mathrm{~h}$ at various test temperatures.

\subsection{Electromagnetic parameters}

Fig. 6 shows zero-field complex permittivity properties of home-made YIG ceramic circle (the fabricated YIG ceramics were grinded into powder, homogenously mixed with paraffin by a mass ratio of $3: 7$, and thereafter formed into a $2 \mathrm{~mm}$ thick circle with an inner diameter of $3 \mathrm{~mm}$ and an outer diameter of $7 \mathrm{~mm}$ ). Along with the frequency increasing from 2 to $18 \mathrm{GHz}$, the changing trend of real part $\varepsilon^{\prime}$ (the ability for the storage of electrical energy) and the imaginary part $\varepsilon$ "' (the dissipation capacity of electrical energy) is just the opposite, and some relaxation peaks are clearly observed as a result of multiple relaxation processes, as shown in Fig.6 (a). [21] In addition, the dielectric loss tangent $\tan \delta_{\varepsilon}$ determined by $\varepsilon^{\prime \prime} / \varepsilon^{\prime}$ fluctuates with the frequency, and interestingly, $\tan \delta_{\varepsilon}$ at about $6 \sim 7$ $\mathrm{GHz}$ and $11 \sim 12 \mathrm{GHz}$ is extremely low suitable for practical microwave devices, as shown 
in Fig. 6(b). As we know, the dielectric loss is ascribed to conduction loss and polarization relaxation loss. And, polarization relaxation loss can be characterized by the Cole-Cole semicircle, that is, a simple semicircle in the $\varepsilon^{\prime} \varepsilon^{\prime \prime}$-coordinate plane means a polarization relaxation process. As shown in Fig. 6(c), there are three semicircles suggesting that the dielectric loss is determined by multiple dielectric relaxation losses, and this result is in accordance with relaxation peaks in Fig. 6(a). [22] Future work will be focused on dielectric properties of YIG ceramics under applied magnetic field in a wide range of frequency.
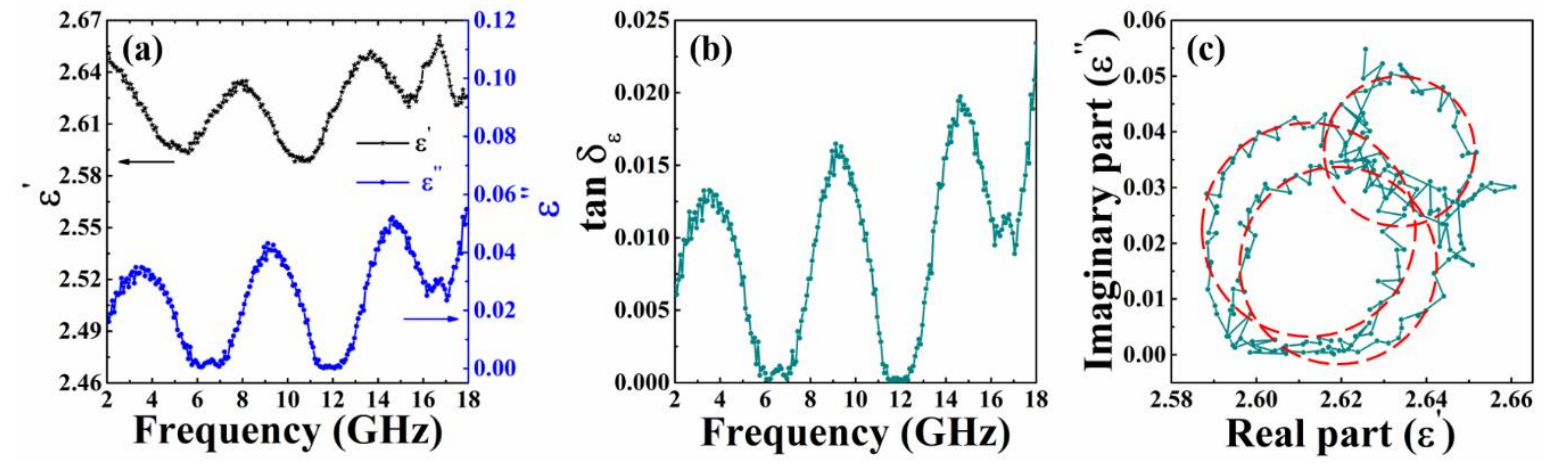

Fig. 6. Frequency dependence of (a) $\varepsilon^{\prime}$ and $\varepsilon^{\prime \prime}$, (b) $\tan \delta_{\varepsilon}$, and (c) Cole-cole semicircle of YIG ceramics sintered at $1400^{\circ} \mathrm{C}$ for $8 \mathrm{~h}$.

For complex permeability, the real part $\mu^{\prime}$ (the ability for the storage of magnetic energy) and the imaginary part $\mu^{\prime \prime}$ (the dissipation capacity of magnetic energy) have the same changing trend along with the rise of frequency from 2 to $18 \mathrm{GHz}$, as shown in Fig. 7(a). Apparently, $\mu^{\prime}$ and $\mu^{\prime \prime}$ exhibit three distinct resonance peaks located at about $6.2 \mathrm{GHz}$, 11.6 GHz and $16.6 \mathrm{GHz}$ in turn, meaning perfect magnetic loss ability at these frequencies, which is well agree with the result of magnetic loss tangent $\tan \delta_{\mu}$ determined by $\mu^{\prime \prime} / \mu^{\prime}$, as shown in Fig. 7(b). Generally, the magnetic loss contains exchange resonance, natural resonance and eddy current loss in the investigated frequency from $2 \mathrm{GHz}$ to $18 \mathrm{GHz}$. 
According to previous report, if the eddy current loss is the only reason for the magnetic loss, frequency dependence of $C_{0}=\frac{\mu^{\prime \prime}}{\mu^{\prime 2} f}$ should be a constant. [23] In Fig. 7(c), $C_{0}$ is nearly constant with little fluctuations at the range of $5 \sim 18 \mathrm{GHz}$, suggesting that the eddy current loss dominates the magnetic loss but also the exchange resonance may exist. As for lower frequency between $2 \mathrm{GHz}$ and $5 \mathrm{GHz}$, the natural resonance will always dominate. The electromagnetic wave (EMW) dissipation is both rely on the dielectric loss and magnetic loss. For our YIG ceramics, values of $\tan \delta_{\varepsilon}$ and $\tan \delta_{\mu}$ were pretty low, indicating that this material may have a good EMW absorption ability, on which future work will be focused.
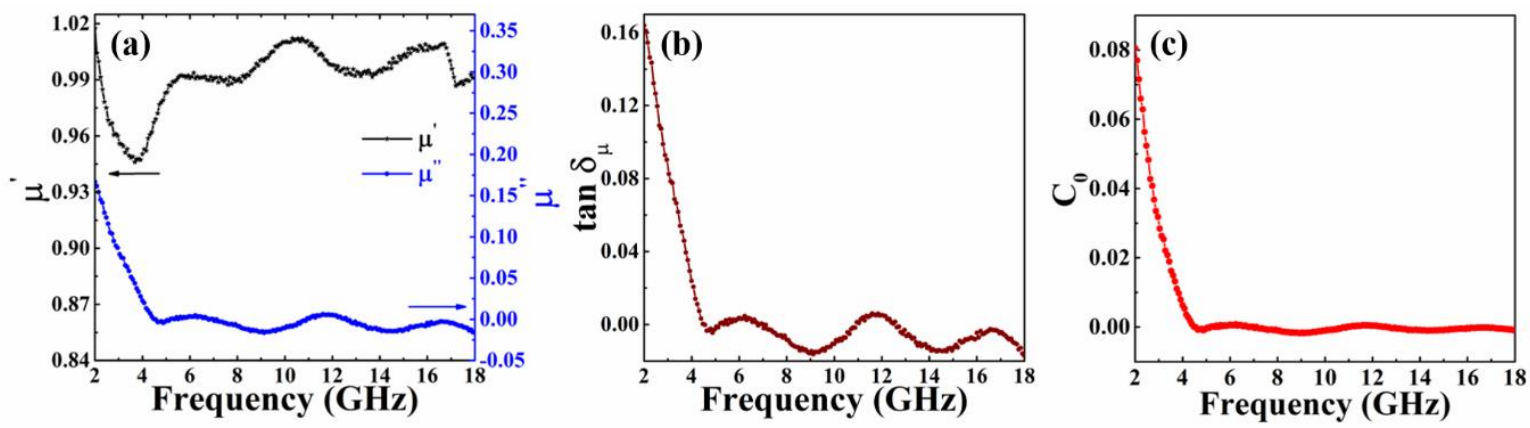

Fig. 7. Frequency dependence of (a) $\mu^{\prime}$ and $\mu^{\prime \prime}$, (b) $\tan \delta_{\mu}$, (c) $\mathrm{C}_{0}$ of YIG ceramics sintered at $1400{ }^{\circ} \mathrm{C}$ for $8 \mathrm{~h}$.

\section{Conclusion}

In this study, pure phase YIG ceramics were successfully produced by tape-casting forming process and one-step solid-state reaction method. The microstructure of the YIG ceramics sintering at $1400{ }^{\circ} \mathrm{C}$ for $10 \mathrm{~h}$ showed a clear grain structure with an obvious grain boundary, and no pores were observed in the SEM images. At $1450{ }^{\circ} \mathrm{C}$ with a holding time of $8 \mathrm{~h}$, the relative density of the YIG ceramic was nearly $99.8 \%$. The activation energy was calculated to be $183.81 \mathrm{~kJ} / \mathrm{mol}$. The saturation magnetization was $28.2 \mathrm{emu} / \mathrm{g}$ at $300 \mathrm{~K}$. 
And, hysteresis loss at $30 \mathrm{~K}$ was as high as $238.8 \mathrm{~mJ} / \mathrm{kg}$, while values of that at temperatures of $230-360 \mathrm{~K}$ was smaller than $10 \mathrm{~mJ} / \mathrm{kg}$. The $\tan \delta_{\varepsilon}$ was nearly zero at $6 \sim 7$ $\mathrm{GHz}$ and $11 \sim 12 \mathrm{GHz}$. The low values of $\tan \delta_{\varepsilon}$ and $\tan \delta_{\mu}$ indicates that it may have a good electromagnetic wave absorption ability. This work provided a new fabrication method for much higher dense and purity fine-grained YIG ceramics. And the future work will be focused on the study of the uptown point $(230 \mathrm{~K})$ on the hysteresis loss chart, the dielectric properties under applied magnetic field in a wider range of frequency and the EMW absorption of the dense YIG ceramics.

\section{Acknowledgments}

This work was supported by the National Key R\&D Program of China (2017YFB0403200) and the National Nature Science Foundation of China (No. 51872327).

\section{References}

[1] R. Valenzuela, Magnetic ceramics, Cambridge University Press, New York, 1994.

[2] D. Badahur, Current Trends in Applications of Magnetic Ceramic Materials, B. Mater. Sci. 15 (1992) 431-439.

[3] J.D. Adam, L.E. Davis, G.F. Dionne, E.F. Schloemann, S.N. Stitzer, Ferrite devices and materials, IEEE T. Microw. Theory. 50 (2002) 721-737.

[4] C. Nan, M.I. Bichurin, S. Dong, D. Viehland, G. Srinivasan, Multiferroic magnetoelectric composites: Historical perspective, status and future directions, J. App. Phys. 103 (2008) 031101. 
[5] M. Huang, S.Y. Zhang, Growth and characterization of rare-earth iron garnet single crystals modified by bismuth and ytterbium substituted for yttrium, J. Mater. Chem. Phys. 73 (2002) 314-317.

[6] M. Huang, Z.C. Xu, Liquid phase epitaxy growth of bismuth-substituted yttrium iron garnet thin films for magneto-optical applications, Thin Solid Films, 450 (2004) 324328.

[7] J.L. Deschanvres, M. Langlet, B. Bochu, J.C. Joubert, Growth of Bi-substituted YIG thin films for magneto-optic applications, J. Magn. Magn. Mater. 101 (1991) 224-226.

[8] N. Kimzuka, T. Katsura, Standard free energy of formation of $\mathrm{YFeO}_{3}, \mathrm{Y}_{3} \mathrm{Fe}_{5} \mathrm{O}_{12}$ and a new compound $\mathrm{YFe}_{2} \mathrm{O}_{4}$ in the $\mathrm{Fe}_{2} \mathrm{O}_{3}-\mathrm{Y}_{2} \mathrm{O}_{3}$ system at $1200{ }^{\circ} \mathrm{C}$, J. Solid State Chem. 13 (1975) 176-181.

[9] F. Sánchez-De Jesús, C.A. Cortés, R. Valenzuela, S. Ammar, A.M. Bolarín-Miró, M. Bolarin-Miro, Synthesis of $\mathrm{Y}_{3} \mathrm{Fe}_{5} \mathrm{O}_{12}$ (YIG) Assisted by High-energy Ball Milling, Ceram. Int. 38 (2012) 5257-5263.

[10] W.F.F.W. Ali, M. Othman, M.F. Ain, N.S. Abdullah, Z.A. Ahmad, The Investigation of the Phenomenological YIG Phase Formation Within $1000{ }^{\circ} \mathrm{C}$ to $1250{ }^{\circ} \mathrm{C}$ : A Kinetic Approach, J. Am. Ceram. Soc. 99 (2015) 315-323.

[11] V. Buscaglia, F. Caracciolo, C. Bottino, M. Leoni, P. Nanni, Reaction diffusion in the $\mathrm{Fe}_{2} \mathrm{O}_{3}-\mathrm{Y}_{2} \mathrm{O}_{3}$ system, Acta Mater. 45 (1997) 1213-1224.

[12] A. Sztaniszláv, E. Sterk, L. Fetter, M. Farkas-Jahnke, J. Lábár, Investigation of garnet formation by sintering of $\mathrm{Y}_{2} \mathrm{O}_{3}$ and $\mathrm{Fe}_{2} \mathrm{O}_{3}$, J. Magn. Magn. Mater. 41 (1984) 75-78.

[13] W.F.F.W. Ali, M. Othman, M.F. Ain, N.S. Abdullah, Z.A. Ahmad, The behavior of high frequency tunable dielectric resonator antenna (DRA) with the addition of excess $\mathrm{Fe}_{2} \mathrm{O}_{3}$ in $\mathrm{Y}_{3} \mathrm{Fe}_{5} \mathrm{O}_{12}$ (YIG) formulation, J. Mater. Sci-Mater. El. 25 (2014) 560-572. 
[14] W.F.F.W. Ali, M. Othman, M.F. Ain, N.S. Abdullah, Z.A. Ahmad, Studies on the formation of yttrium iron garnet (YIG) through stoichiometry modification prepared by conventional solid-state method, J. Eur. Ceram. Soc. 33 (2013) 1317-1324.

[15] X. Li, J. Zhou, J. Deng, H. Zheng, L. Zheng, P. Zheng, H. Qin, Synthesis of Dense, Fine-Grained YIG Ceramics by Two-Step Sintering, J. Electron. Mater. 45 (2016) 4973-4978.

[16] F. Chen, Q. Li, X. Wang, J. Ouyang, Y. Nie, Z. Feng, R. Gong, Y. Chen, V.G. Harris, Crystal structure tailored microwave magnetodielectric in $\mathrm{Yb}_{\mathrm{x}} \mathrm{Y}_{3-\mathrm{x}} \mathrm{Fe}_{5} \mathrm{O}_{12}$ ceramics, J. Alloy. Compd. 726 (2017) 1030-1039.

[17] Vapor Pressure of the Metallic Elements, in: David R. Lide (Eds.), CRC Handbook of Chemistry and Physics, 84th Edition, online version. CRC Press. Boca Raton, Florida, 2003.

[18] W.F.F.W. Ali, M. Othman, M.F. Ain, N.S. Abdullah, Z.A. Ahmad, Sintering and grain growth control of high dense YIG, Ceram. Int. 42 (2016) 13996-14005.

[19] M.N. Rahaman, ceramic processing and sintering, 2nd ed. M. Dekker Inc. New York, 2003.

[20] P.B.A. Fechine, E.N. Silva, A.S. de Menezes, J. Derov, J.W. Stewart, A.J. Drehman, I.F. Vasconcelos, A.P. Ayala, L.P. Cardoso, A.S.B. Sombra, Synthesis, Structure and Vibrational Properties of GdIGx:YIG1-X Ferrimagnetic Ceramic Composite, J. Phys. Chem. Sol. 70 (2009) 202-209.

[21] Wu, H., Liu, J., Liang, H., \& Zang, D. (2020). Sandwich-like Fe3O4/Fe3S4 composites for electromagnetic wave absorption. Chemical Engineering Journal, 393(March), 124743. 
[22] Zou, J., Wang, Z., Yan, M., \& Bi, H. (2014). Enhanced interfacial polarization relaxation effect on microwave absorption properties of submicron-sized hollow $\mathrm{Fe} 3 \mathrm{O} 4$ hemispheres. Journal of Physics D: Applied Physics, 47(27).

[23] Lan, D., Qin, M., Yang, R., Chen, S., Wu, H., Fan, Y., Fu, Q., \& Zhang, F. (2019). Facile synthesis of hierarchical chrysanthemum-like copper cobaltate-copper oxide composites for enhanced microwave absorption performance. Journal of Colloid and Interface Science, 533, 481-491. 


\section{Figures}

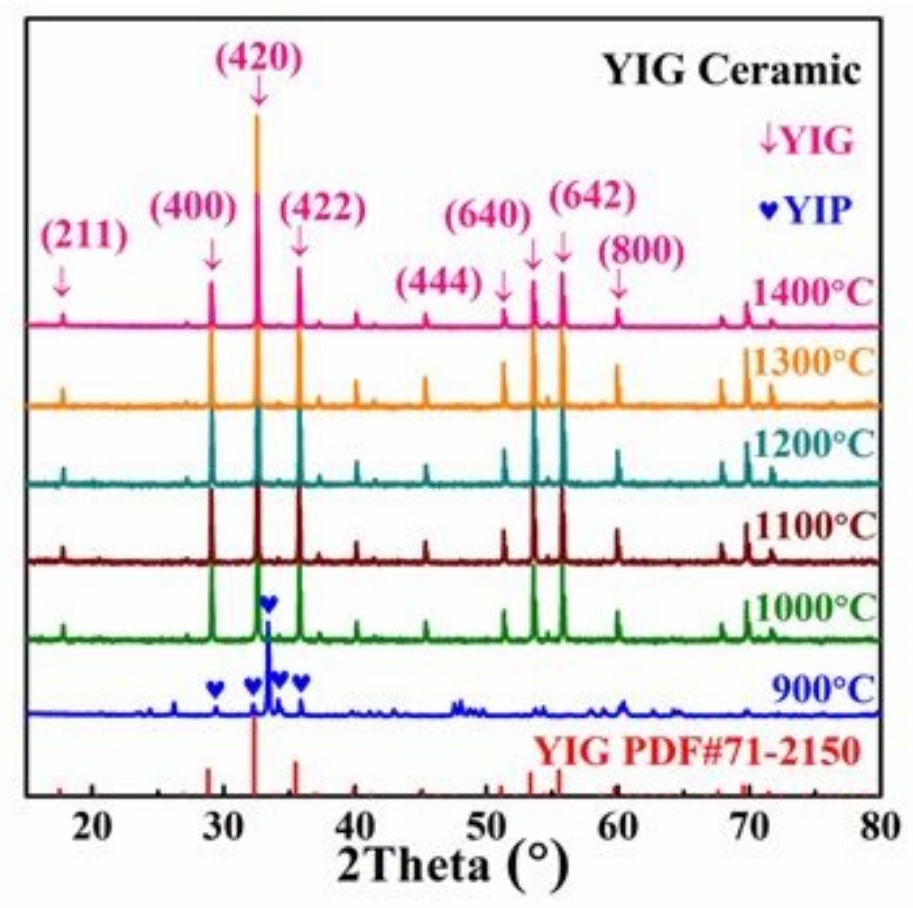

Figure 1

The XRD patterns of YIG ceramics sintered under various temperatures in air atmosphere.

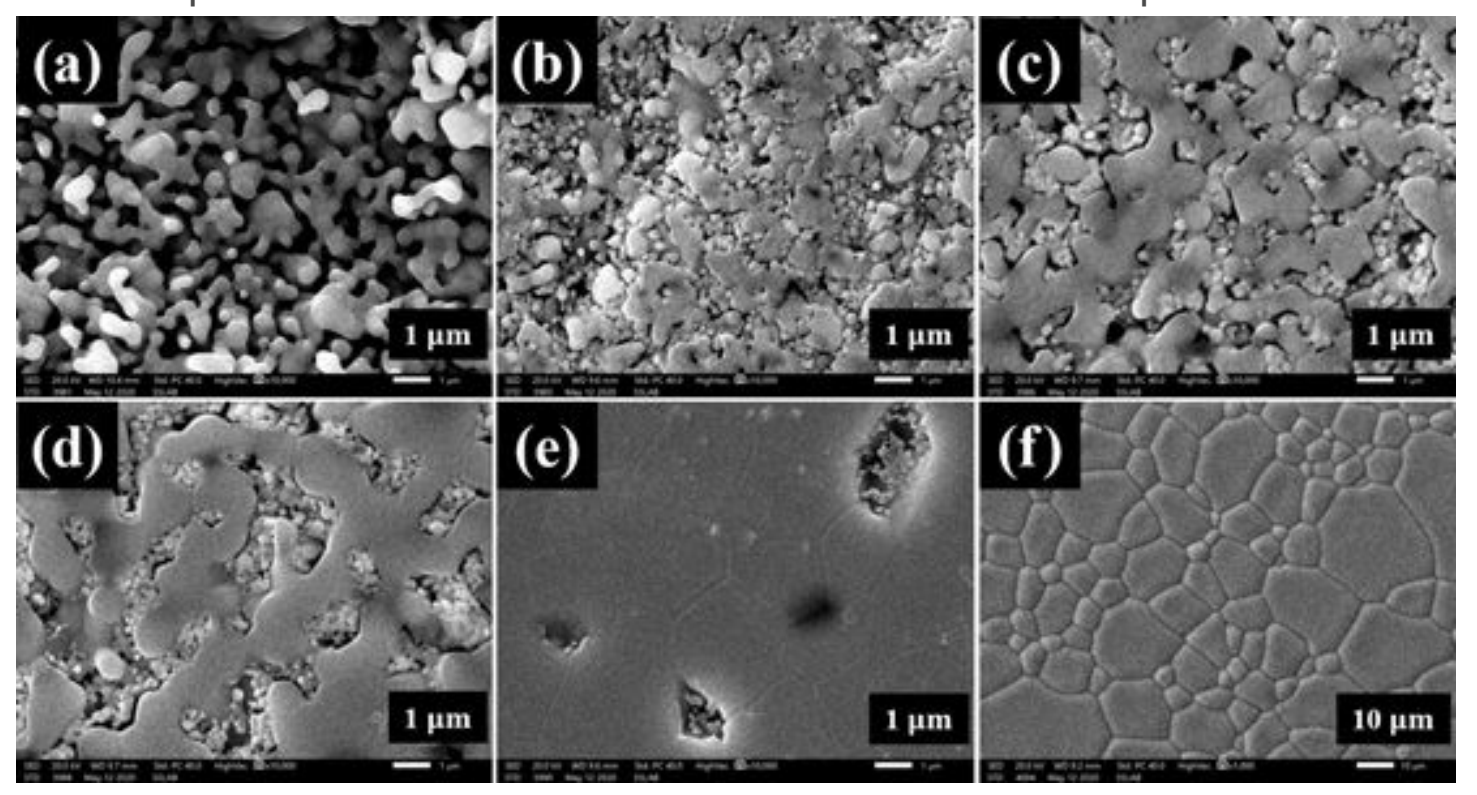

Figure 2

SEM images of YIG ceramics sintered at (a) $900 \otimes$, (b) 1000 , (c) $1100 \otimes$, (d) $1200 \rrbracket$, (e) 1300 and (f) $1400 \otimes$ for $10 \mathrm{~h}$. 

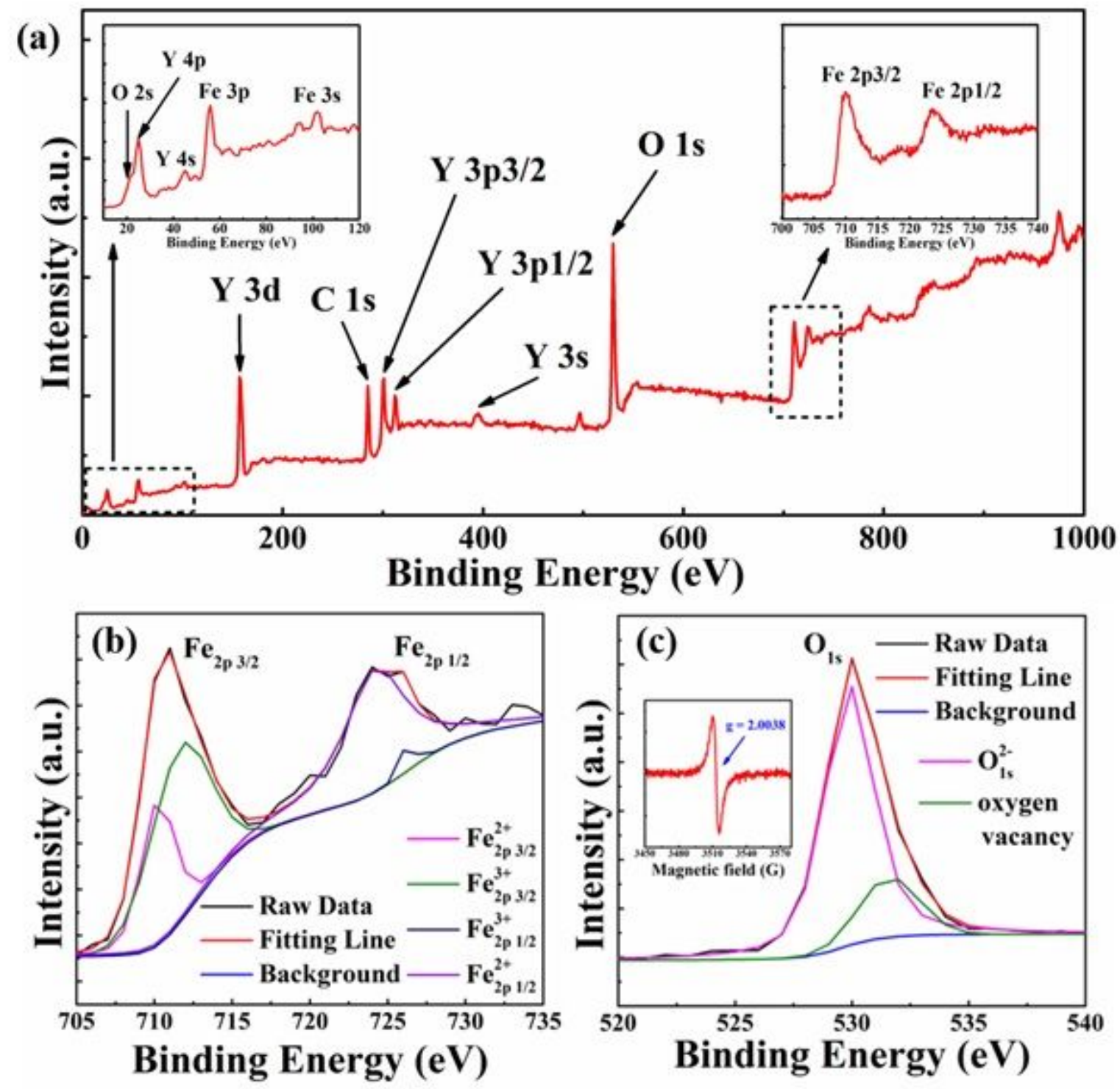

Figure 3

XPS spectra in (a) the survey range, (b) Fe ion and (c) $\mathrm{O}$ ion in YIG ceramics sintered at $1400 \otimes$ for $10 \mathrm{~h}$.
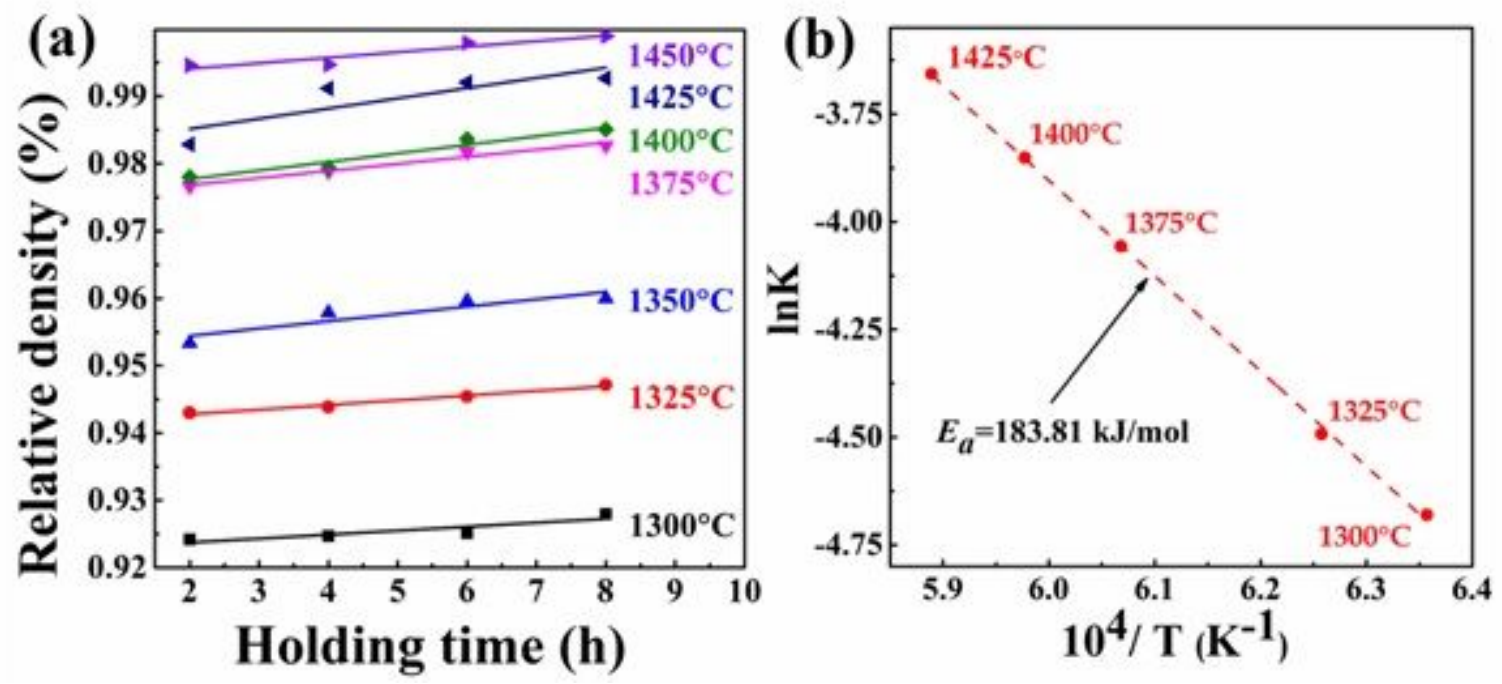
Figure 4

(a) Relative densities of YIG ceramics sintered at various temperatures and holding times. (b) The activation energy analysis for YIG ceramics.
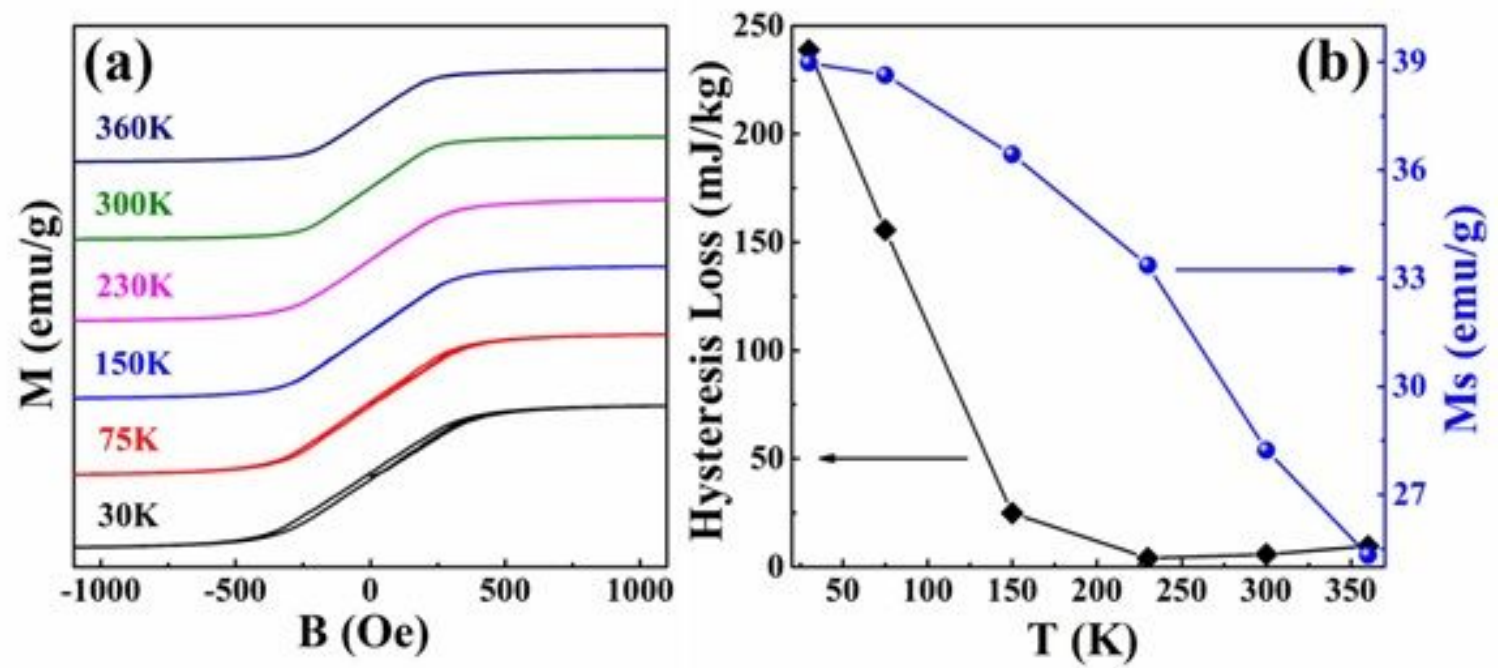

Figure 5

(a) Magnetic hysteresis loops and (b) Ms and hysteresis loss of YIG ceramics sintered at $1400{ }^{\circ} \mathrm{C}$ for $8 \mathrm{~h}$ at various test temperatures.
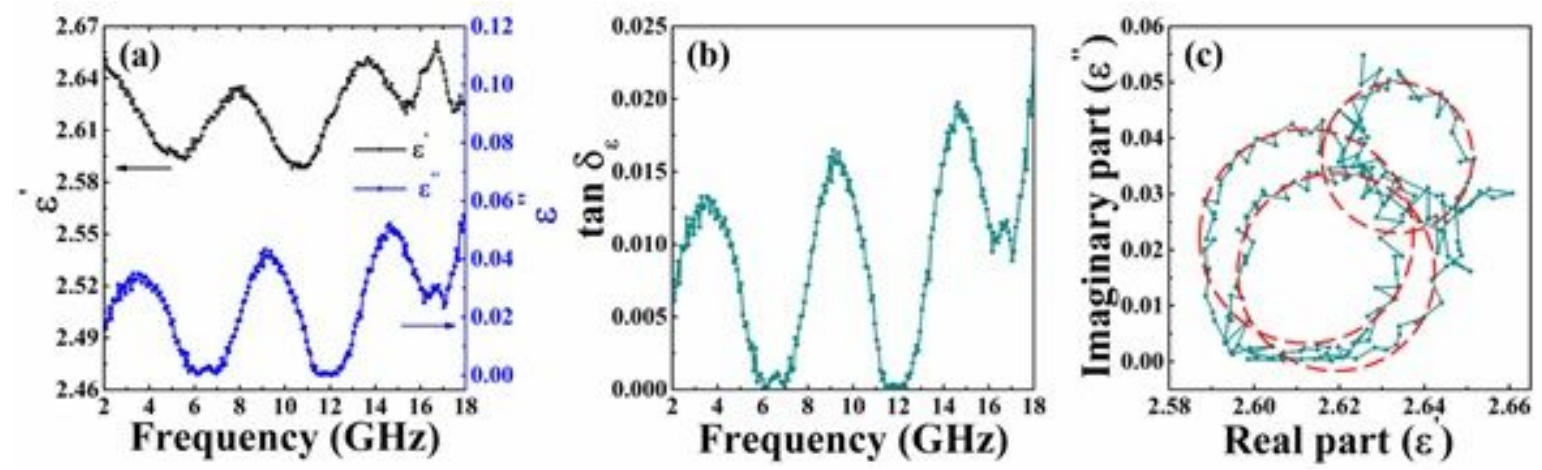

Figure 6

Frequency dependence of (a) $\varepsilon^{\wedge^{\prime}}$ and $\varepsilon^{\wedge \prime}$, (b) tan $\delta_{-} \varepsilon$, and (c) Cole-cole semicircle of YIG ceramics sintered at $1400^{\circ} \mathrm{C}$ for $8 \mathrm{~h}$.
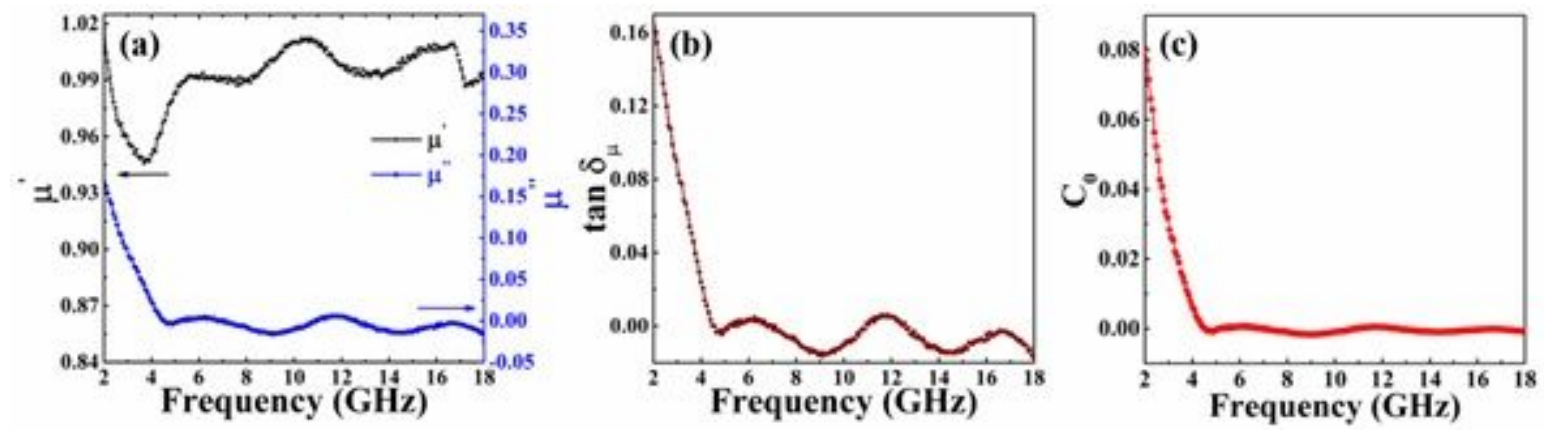

Figure 7 
Frequency dependence of (a) $\mu^{\wedge \prime}$ and $\mu^{\wedge \prime \prime}$, (b) tand_ $\mu$, (c) C0 of YIG ceramics sintered at $1400{ }^{\circ} \mathrm{C}$ for $8 \mathrm{~h}$. 